\section{Aquisição do aspecto perfect por falantes nativos de espanhol da Argentina aprendizes de português como L2}

The acquisition of the perfect aspect by native speakers of Spanish spoken in Argentina learners of Portuguese as L2

Jean Carlos da Silva GOMES (UFRJ) gomes.jean@outlook.com

Recebido em: 05 de jan. de 2019. Aceito em: 28 de abr. de 2019.
GOMES, Jean Carlos da Silva.

Aquisição do aspecto perfect por

falantes nativos de espanhol da

Argentina aprendizes de português como L2. Entrepalavras, Fortaleza, v.

9, n. 2, p. 354-377, maio-ago/2019.

Resumo: $O$ aspecto perfect relaciona dois pontos na linha do tempo, sendo eles o momento do evento e o momento da referência. Quando associado ao tempo presente, descreve uma situação que começou no passado e persiste até o presente (perfect universal) ou uma ação que ocorreu no passado e apresenta relevância no presente (perfect existencial). Uma das formas de realizar linguisticamente essa noção aspectual é por meio do passado composto que, no espanhol, veicula perfect universal e existencial, enquanto que, no português, expressa somente o subtipo universal. Neste trabalho, investigamos o processo de aquisição do aspecto perfect por falantes nativos do espanhol da Argentina aprendizes de português como L2. Para tanto, foram aplicados dois testes linguísticos a estudantes de português em níveis intermediário e avançado. Os resultados indicam que os aprendizes, independentemente do nível em que se encontram, transferem padrões de realização morfossintática do aspecto perfect de sua L1 para a L2, uma vez que utilizam o passado composto também para realizar o subtipo existencial.

Palavras-Chave: Aspecto perfect. Aquisição de L2. Espanhol da Argentina. Português. 
Abstract: The perfect aspect relates two points on the timeline: the moment of the event and the moment of reference. When associated with the present tense, it describes a situation that began in the past and persists to the present (universal perfect) or an action that occurred in the past and presents relevance in the present (existential perfect). One of the ways to perform linguistically this aspectual notion is by means of the present perfect that, in Spanish, conveys universal perfect and existential perfect, whereas in Portuguese, it expresses only the universal subtype. In this work, we investigated the process of acquisition of the perfect aspect by native speakers of the Spanish spoken in Argentina learners of Portuguese as L2. To this end, two linguistic tests were applied to Portuguese language students who were in intermediate and advanced levels. The results indicated that learners, regardless of their level, transfer morphosyntactic performance patterns from the perfect aspect of their L1 to L2, since they use the present perfect also to perform the existential subtype.

Keywords: Perfect aspect. L2 acquisition. Spanish spoken in Argentina. Portuguese.

\section{Introdução}

Aspecto, segundo Comrie (1976), pode ser definido como a categoria linguística que se refere às distintas formas de se visualizar a composição temporal interna de uma situação. O aspecto perfect, de acordo com Pancheva (2003), descreve um intervalo de tempo que relaciona o momento do evento ao momento da referência, sendo o primeiro anterior ao segundo.

Esse aspecto pode ser subdividido em dois tipos: o universal e o existencial (IATRIDOU; ANAGNOSTOPOULOU; IZVORSKI, 2003). Quando associados ao tempo presente, o primeiro descreve uma situação que iniciou no passado e persiste até o presente, enquanto que o segundo descreve uma situação que ocorreu no passado e tem relevância no presente.

O perfect universal (PU), quando relacionado ao tempo presente, pode ser realizado linguisticamente, no português do Brasil (PB) e no espanhol da Argentina (EA), por meio do passado composto, do presente do indicativo e das perífrases progressivas. O perfect existencial (PE), por sua vez, pode ser expresso, no PB, por meio do passado simples enquanto que, no EA, pode ser realizado por meio do passado simples ou composto.

Como se pode ver, o passado composto, no EA, permite a veiculação dos dois subtipos de perfect, enquanto que, no $\mathrm{PB}$, expressa apenas PU. De acordo com De Paula Scott (1995), Akerberg (2006) e Maggessy (2018), na interlíngua, sistema linguístico que caracteriza a produção do falante nativo em estágios da aquisição de uma segunda língua, de hispanofalantes aprendizes de português como L2, é comum a transferência do padrão morfossintático de realização de perfect, uma vez que, em seus estudos sobre a produção de falantes nativos do 
v. 9 (2)

$354-377$ maio-ago 2019

espanhol do México, identificaram que os aprendizes utilizam o passado composto na L2 também para expressar o PE.

Diante disso, o objetivo deste trabalho é investigar o processo de aquisição do aspecto perfect por falantes nativos do EA aprendizes de português como L2. Mais especificamente, pretende-se investigar se os falantes dessa variedade também transferem o padrão morfológico de sua L1 para a L2.

\section{0 aspecto perfect}

A categoria linguística de aspecto pode ser dividida em dois tipos: aspecto semântico, referente aos valores inerentes aos itens lexicais que compõem uma sentença; e aspecto gramatical, referente aos valores presentes na morfologia verbal (COMRIE, 1976)․․

O perfect, um aspecto gramatical, é definido, na teoria do agora estendido (Extended Now) ${ }^{2}$, como um intervalo de tempo conhecido como perfect time span (PTS) ${ }^{3}$, que inclui o momento do evento e se estende até o momento de referência, podendo este coincidir com o presente, o passado ou o futuro ${ }^{4}$. Dessa forma, o perfect relaciona uma situação a dois pontos no tempo.

Segundo Comrie (1976), o aspecto perfect, quando associado ao tempo presente, apresenta uma relação entre uma situação passada e o tempo presente. Os exemplos em (1) e (2) exemplificam sentenças que veiculam perfect e que não veiculam esse aspecto, respectivamente.

(1) I have lost my penknife.

'Eu tenho perdido meu canivete'

(Eu perdi meu canivete)

(2) I lost my penknife.

'Eu perdi meu canivete'

(Eu perdi meu canivete) ${ }^{5}$

\footnotetext{
${ }^{1}$ Ainda que a categoria de aspecto, de acordo com alguns autores, seja descrita como aquela que inclui também fatores de natureza discursiva e pragmática, neste trabalho, baseamo-nos em pressupostos da teoria gerativa, de modo que restringimos à análise do fenômeno estudado aos níveis morfossintático e lexical.

${ }^{2}$ Há outras teorias que buscam descrever e explicar o aspecto perfect, como a teoria da relevância atual e a teoria do estado de perfect. Neste trabalho, baseamo-nos nos pressupostos da teoria do agora estendido.

3 Em português: intervalo de tempo de perfect.

${ }_{4}^{4}$ Neste trabalho, investigamos o perfect relacionado ao tempo presente.

${ }^{5}$ Exemplos extraídos de Comrie (1976).
} 
A sentença em (1) apresenta o aspecto perfecte, por isso, indica que o canivete continua perdido. Nesse caso, o estado proveniente da ação de "perder o canivete" se estende até o presente. A sentença em (2), por sua vez, apresenta apenas o aspecto perfectivo, ou seja, a ação é vista como um todo e, dessa forma, a ação de "perder o canivete" não é relevante no presente, ainda que continue perdido.

Iatridou, Anagnostopoulou e Izvorski (2003) propuseram uma subdivisão do aspecto perfect em dois tipos: PU e PE. ${ }^{6} \mathrm{O}$ primeiro, quando associado ao tempo presente, refere-se a uma situação que se iniciou no passado e persiste até o presente, como podemos ver em (3). Enquanto que o segundo, quando associado ao tempo presente, descreve uma situação que se iniciou e terminou no passado, mas que ainda apresenta efeitos no presente, conforme vemos em (4).

(3) He estudiado mucho últimamente.

'Tenho estudado ultimamente.'

(4) Ya he viajado a México.

'Já viajei para o México.'

O perfect não se opõe aos dois aspectos básicos: perfectivo ou imperfectivo. Dessa forma, uma sentença que veicula PU, necessariamente, também carrega o valor de imperfectivo, enquanto que, em uma sentença em que há o $\mathrm{PE}$, necessariamente, também carrega perfectivo. Entretanto, os aspectos perfectivo e imperfectivo podem ser veiculados sem a presença do perfect.

\section{As realizações do aspecto perfect no espanhol da Argentina e no português do Brasil}

$O$ aspecto perfect pode ser realizado linguisticamente por meio de distintas formas verbais a depender das línguas. Nespoli (2018) verificou que, nas línguas românicas, há uma sistematização entre as realizações desse aspecto e os advérbios que auxiliam em sua veiculação. Neste trabalho, apresentamos as formas de realização do perfect no EA e no PB.

Segundo Fontanella De Weinberg (2004), há sete zonas dialetais na Argentina. Neste trabalho, restringimo-nos a informações

\footnotetext{
${ }^{6}$ Há outras subdivisões para o aspecto perfect, como a de Comrie (1976), que o divide em quatro tipos; ou a de Pancheva (2003), que o classifica em três. Neste trabalho, optou-se por utilizar a classificação em dois tipos, pois, segundo Novaes e Nespoli (2014), essa proposta captura uma generalização semântica e é mais enxuta.
} 
V. 9 (2)

$354-377$

maio-ago

2019

referentes à Região do Litoral, que corresponde a Buenos Aires, quase totalidade de Santa Fé; zonas de Entre Rios; La Pampa e Patagônia. ${ }^{7}$ A cidade mais povoada dessa região, de acordo com censo argentino de 2010, é Rosário.

O PU, no EA, pode ser realizado por meio do passado composto (ARAÚJO, 2013), como podemos ver no exemplo em (5), e também pela perífrase progressiva, formada por "estar" + gerúndio (BURGOS, 2015), conforme o exemplo em (6).

(5) Desde 2001 Juan ha actuado como director del equipo.

'Desde 2001, João tem atuado como diretor do time.'

(6) Desde 2001 Juan está actuando como director del equipo.

'Desde 2001, João está atuando como diretor do time.'

Vale destacar que Araújo (2013) e Burgos (2015) não tinham por objetivo elencar as possíveis realizações de perfect em seus estudos, de modo que parece relevante citar aqui outras formas de realizar essa noção aspectual no EA que não estão descritas nesses trabalhos.

Parece plausível mencionar que o presente do indicativo também está a serviço da realização de PU, como no exemplo em (7). Além disso, é perceptível que as perífrases progressivas não admitem somente o verbo "estar" como auxiliar. Outros como "seguir", "andar", "venir" parecem servir nessas construções, como vemos em (8).

(7) Desde 2001 Juan actúa como director del equipo.

'Desde 2001, João atua como diretor do time.'

(8) Desde 2001 Juan sigue actuando como director del equipo.

'Desde 2001, João segue atuando como diretor do time.'

O PE, por sua vez, pode ser veiculado, no EA, por meio do passado composto (ARAÚJO, 2013), conforme vemos em (9), ou por meio do passado simples (DUARTE, COAN e PONTES, 2016), como no exemplo em (10).

(9) Juan ya ha pagado la cuenta.

'João já pagou a conta.'

\footnotetext{
${ }^{7}$ A escolha pela região do Litoral se deu pelo fato de que os participantes desta pesquisa são falantes nativos dessa área dialetal. Desse modo, não consideramos pertinente, neste artigo, discorrer sobre as diferenças na realização do aspecto perfect em outras regiões dialetais da Argentina.
} 
(10) Juan ya pagó la cuenta.

'João já pagou a conta.'

Como visto até aqui, o passado composto é uma forma verbal capaz de veicular tanto o subtipo universal quanto existencial na variedade de espanhol falada na região do litoral da Argentina. No tocante ao contraste entre as formas simples e composta, de acordo com Araújo (2013) e Duarte, Coan e Pontes (2016), de uma maneira geral, os falantes dessa variedade tendem a usar com mais frequência a forma simples, ainda que esteja acompanhada de marcadores temporais que indiquem relevância no presente. ${ }^{8}$

No PB, segundo Novaes e Nespoli (2014), o PU pode ser expresso por meio de três formas linguísticas. A primeira delas é o passado composto, formado pelo verbo "ter" no tempo presente acompanhado de um verbo no particípio, como no exemplo em (11). A segunda é por meio das perífrases progressivas, formadas por um verbo auxiliar e outro no gerúndio, conforme o exemplo em (12). E a terceira é por meio do presente do indicativo, por exemplo em (13).

(11) João tem trabalhado muito ultimamente.

(12) João está trabalhando muito ultimamente.

(13) João trabalha muito ultimamente.

O passado composto é considerado a forma verbal prototípica para realizar o PU no PB, uma vez que essa morfologia expressa somente essa noção aspectual. Por outro lado, as perífrases progressivas e o presente do indicativo podem veicular outros valores aspectuais, como vemos nos exemplos em (14) e (15). Nesses casos, essas formas verbais expressam, respectivamente, uma ação em andamento e um hábito, sem descrever uma ação que se iniciou no passado e que persiste até o presente.

(14) João está tomando banho.

(15) João toma banho todos os dias.

Por outro lado, Jesus et al (2017) afirmam que o passado composto está deixando de ser a forma mais usual para veicula PU na

\footnotetext{
${ }_{8}^{8}$ Diversos apontamentos foram feitos por estudiosos que buscavam compreender 0 comportamento do passado composto nas áreas dialetais da Argentina. Neste trabalho, não buscamos expor esses detalhes, uma vez que não apresentam grande relevância para esta investigação.
} 
v. 9 (2)

354-377 maio-ago 2019

fala, restringindo-se à escrita. Além disso, ainda que sirva à expressão dessa noção aspectual, em alguns casos, o uso do passado composto não parece muito aceitável no PB. Uma das evidências dessa possível restrição seria a sentença "João tem namorado Camila desde 2015". Em um caso como esse, parece não haver um consenso quanto à gramaticalidade dessa construção no PB.

Para Mendes (2004), a forma "estar" + gerúndio é a mais recorrente, quando comparada ao passado composto, para realizar o PU. Jesus et al (2017), ao comparar as três formas de realizações possíveis, identificaram que o presente simples parece ser a opção mais utilizada pelos falantes na oralidade.

O PE, por sua vez, pode ser expresso no PB por meio do passado simples acompanhado de uma informação adicional (NOVAES; NESPOLI, 2014), como no exemplo em (16). Essa informação adicional pode ser um advérbio, como "já", "recentemente", "agora", "ainda não", a presença de outra sentença ou ainda por meio do contexto. Matos (2016) destaca também que esse aspecto pode ser expresso pela locução "acabar de" + infinitivo, como no exemplo em (17).

(16) João já leu um livro em inglês.

(17) João acabou de chegar.

Nespoli (2018), ao investigar as realizações do aspecto perfect nas línguas românicas, o que inclui o espanhol e o português, formulou uma lista de advérbios e expressões adverbiais que estão a serviço desse aspecto nessas línguas. No quadro 1, a seguir, podemos visualizar a proposta dessa autora.

Quadro 1 - Advérbios e expressões adverbiais em contexto de realização de perfect

\begin{tabular}{|l|l|l|}
\hline ADVÉRBIO / EXPRESSÃO ADVERBIAL & UNIVERSAL & EXISTENCIAL \\
\hline Sempre & $\mathrm{X}$ & \\
\hline Ultimamente & $\mathrm{X}$ & \\
\hline Desde X tempo & $\mathrm{X}$ & \\
\hline Há/Faz X tempo & $\mathrm{X}$ & \\
\hline Ainda & $\mathrm{X}$ & \\
\hline Até X tempo (no presente) & $\mathrm{X}$ & \\
\hline Nunca & $\mathrm{X}$ & $\mathrm{X}$ \\
\hline Já & & $\mathrm{X}$ \\
\hline Ainda não & & $\mathrm{X}$ \\
\hline
\end{tabular}

Fonte: Nespoli (2018, p. 138). 
Com base nas descrições feitas até aqui, no quadro 2, a seguir, apresentamos uma comparação entre as realizações linguísticas dos subtipos do aspecto perfect no EA e no PB.

Quadro 2 - Comparação entre o espanhol da Argentina e o português do Brasil quanto às realizações do aspecto perfect

\begin{tabular}{|l|c|c|c|c|}
\hline \multirow{2}{*}{\begin{tabular}{c}
\multirow{2}{*}{ FORMA } \\
LINGUÍSTICA
\end{tabular}} & \multicolumn{2}{|c|}{ EA } & \multicolumn{2}{c|}{ PB } \\
\cline { 2 - 5 } & PU & PE & PU & PE \\
\hline Passado composto & $\mathrm{X}$ & $\mathrm{X}$ & $\mathrm{X}$ & \\
\hline Perífrases progressivas & $\mathrm{X}$ & & $\mathrm{X}$ & \\
\hline Presente do indicativo & $\mathrm{X}$ & & $\mathrm{X}$ & \\
\hline Passado simples & & $\mathrm{X}$ & & $\mathrm{X}$ \\
\hline
\end{tabular}

Fonte: Elaborado pelo autor.

De acordo com White (2003), quando um fenômeno linguístico funciona de maneira diferente em duas línguas e é subdeterminado pelo input para os aprendizes de língua estrangeira, é possível realizar um estudo de aquisição de L2. Visto que foram encontradas diferenças na realização do aspecto perfect entre o EA e o PB e que tais distinções não podem ser baseadas na frequência de ocorrência dada no input ou com base em analogia, propomos, neste estudo, uma análise do processo de aquisição desse aspecto por falantes nativos do EA aprendizes de português como L2 ${ }^{9}$.

\section{A aquisição do aspecto perfect por hispanofalantes aprendizes de português como L2}

Uma vez que o espanhol e o português sejam considerados idiomas próximos, é comum que os aprendizes encontrem uma simetria entre o sistema temporal-aspectual dessas línguas. No tocante às realizações do aspecto perfect, como citado na segunda seção deste artigo, percebemos que a diferença entre elas centra-se, principalmente, nos valores expressos pelo passado composto.

De Paula Scott (1995) afirma que falantes nativos de espanhol aprendizes de português como L2, em sua interlíngua, utilizam o passado composto em contextos que exigem o passado simples, gerando frases agramaticais. Em seu estudo sobre a produção de aprendizes falantes nativos do espanhol do México (EM), encontrou produções como as apresentadas em (18) e (19).

9 Entendemos como L2, com base em White (2003), toda língua aprendida após o período de aquisição da linguagem. 
V. 9 (2)

$354-377$

maio-ago

2019

(18) *Ainda não tenho terminado meu trabalho.

(19) *Você já tem almoçado? ${ }^{10}$

Para essa autora, tais dados podem ser entendidos como decorrentes de uma questão puramente aspectual. Pois a distinção entre o passado simples e o composto, no EM, se dá pela maneira como o indivíduo visualiza a ação enquanto que, no $\mathrm{PB}$, o uso do passado composto depende de outros fatores relacionados ao tempo e ao aspecto semântico. A autora conclui que o uso do passado composto em dados como os de (18) e (19) ocorre porque os indivíduos apenas levam em consideração os fatores que diferenciam o passado composto e o simples presentes em sua L1.

Akerberg (2006), ao realizar um estudo sobre o conhecimento acerca da distinção entre o passado simples e composto por falantes nativos do EM aprendizes de português como L2 em nível de graduação, também concluiu que os indivíduos transferem padrões da L1 para a L2.

Em seu estudo, realizou dois testes, um de preenchimento de lacuna e um de tradução. No primeiro, os participantes deveriam escolher entre duas formas verbais, indicando qual delas era a mais adequada para completar a lacuna, como no exemplo em (20). No segundo, os aprendizes deveriam traduzir frases que estavam em espanhol, como a que apresentamos em (21), ao português.

(20) Nunca FUMEI/TENHO FUMADO um cigarro na minha vida.

(21) El centro ha contratado a tres nuevos profesores. ${ }^{11}$

'O centro contratou três novos professores'.

Na aplicação do teste de preenchimento de lacuna, percebeu-se que a presença de advérbios como "ainda não" e "nunca" não auxiliavam no entendimento da forma verbal a ser utilizada para completar a lacuna. Os resultados desse teste não foram muito reveladores, uma vez que a porcentagem de acertos e erros estavam por volta dos 50\%. O teste de tradução, por outro lado, foi bastante esclarecedor, uma vez que indicou que muitos aprendizes não sabiam que o passado composto poderia ser traduzido ao português como passado simples.

Para esse autor, um dos fatores determinantes para a escolha do passado simples em detrimento do passado composto foi o aspecto

\footnotetext{
${ }^{10}$ Exemplos extraídos de De Paula Scott (1995, p. 33-34).

${ }^{11}$ Exemplos extraídos de Akerberg (2006, p. 97, 110).
} 
semântico. Quando os eventos descritos nas sentenças eram télicos, havia altas porcentagens de uso do passado simples e, quando eram pontuais, havia uma quantidade mediana de ocorrências dessa forma

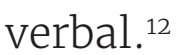

O estudo de Maggessy (2018), por sua vez, tinha por objetivo investigar as realizações do aspecto perfect por falantes de EM aprendizes de português como L2. Em sua metodologia, a autora controlou diversos fatores como tipos de verbo e expressões adverbiais que garantissem a leitura de perfect nas sentenças.

Seus resultados indicaram que os aprendizes transferem os padrões de realização do perfect de sua L1 para a L2, até mesmo em níveis avançados. A autora indicou que os verbos que mais favorecem a transferência da morfologia do passado composto em contextos que geram agramaticalidade no português foram os achievements. Esses resultados se opõem aos de Akerberg (2006), uma vez que os achievements foram entendidos como aqueles que favoreciam o uso da forma simples.

Como podemos ver, a revisão bibliográfica levantada até aqui indica que falantes nativos de espanhol aprendizes de português comumente transferem padrões de sua L1 para a L2 quanto à realização do aspecto perfect. Contudo, esses trabalhos destinavam-se à análise de dados de falantes da variedade mexicana.

Neste estudo, investigamos o modo como falantes de espanhol nativos da região do litoral da argentina aprendizes de português como L2 atuam diante desse fenômeno. Uma das motivações para a escolha dessa variedade diz respeito, principalmente, ao comportamento do passado composto, que se difere da variedade analisada nos estudos anteriores. Diante disso, formulamos duas hipóteses para esta investigação:

(i) falantes de espanhol nativos da região do litoral da Argentina aprendizes de português como L2 em nível intermediário transferem padrões da L1 para L2 quanto à realização do aspecto perfect;

(ii) falantes de espanhol nativos da região do litoral da Argentina aprendizes de português como L2 em nível avançado não transferem padrões da L1 para L2 quanto à realização do aspecto perfect.

${ }^{12} \mathrm{O}$ autor afirma que as diferenças entre os passados em ambas as línguas não podem ser aprendidas apenas pela exposição do input natural. É necessário haver instrução para que haja avanço no conhecimento das regras de uso dessas formas verbais. 
V. 9 (2)

$354-377$

\section{Metodologia}

A fim de atingir os objetivos propostos para este trabalho, foram desenvolvidos dois testes linguísticos, um de preenchimento de lacuna e um de tradução. Os testes foram aplicados a dezessete falantes nativos de espanhol da região do litoral da Argentina com idade entre 22 e 44 anos que cursavam português na graduação pela Universidad Nacional de Rosario. Mais especificamente, todos eram da cidade de Rosário, que, como dito anteriormente, é a cidade mais povoada da região do litoral.

Antes de realizar os testes, os participantes respondiam um conjunto de questões que buscava investigar o perfil dos aprendizes. Com base nas respostas obtidas por meio desse questionário, foi possível verificar que todos os participantes estavam aprendendo a variedade de português falada no Brasil, mas nenhum deles havia morado nesse país. Metade deles utiliza a língua portuguesa em seu trabalho, seja para ensinar ou traduzir, enquanto que a outra metade não a utiliza nesse âmbito.

O primeiro teste realizado foi o de preenchimento de lacuna. Nele, os indivíduos eram apresentados a 18 estímulos, e cada um deles era formado por duas partes. Na primeira, apresentava-se o contexto da situação, formado por uma ou duas sentenças; enquanto que, na segunda parte, era apresentada a sentença que continha uma lacuna a ser completada. Nessa última, havia uma lacuna com um verbo no infinitivo entre parênteses e um advérbio/expressão adverbial que indicava a informação temporal/aspectual a ser veiculada na situação. O participante deveria, então, completar a lacuna conjugando o verbo entre parênteses.

Esse teste consistiu de 6 sentenças-alvo e 12 sentenças distratoras. Das sentenças-alvo, 3 veiculavam PU, como no exemplo em (22), e 3 veiculavam PE, como em (23). Para o primeiro subtipo, foram utilizados advérbios/expressões adverbiais como "ultimamente" e "desde a semana passada até agora" ao passo que, para o segundo, utilizou-se "já", "recentemente" e "ainda não".

(22) Joana quer muito aperfeiçoar o espanhol. Por isso, ultimamente Joana (ler) contos de Horacio Quiroga.

(23) Juliana é uma menina talentosa. Como ela gosta muito de cantar e atuar, decidiu se dedicar à vida artística. Inclusive, já (participar) de um evento na Broadway. 
As sentenças-distratoras, por sua vez, se dividiam em 4 grupos, cada um deles continha 3 sentenças. No primeiro, as sentenças carregavam informação de tempo passado e aspecto perfectivo, identificados por marcadores como "ontem" e "ano passado", por exemplo em (24); No segundo, tempo passado e aspecto imperfectivo, assinalados por "antes" e "antigamente", como em (25); no terceiro, tempo presente, identificado por "agora", "atualmente" e "hoje", como podemos ver em (26); e, por fim, no quarto, tempo futuro, que continha expressões como "amanhã", "ano que vem", "na semana que vem", como visto em (27).

(24) Jonas é muito gordinho, mas ontem

(decidir) fazer uma dieta para emagrecer.

(25) Thiago agora dança tango, mas antigamente só (dançar) funk.

(26) Carolina preparava bolos em uma confeitaria. Agora ela televisão. (cozinhar) em um programa de

(27) Elena gosta muito de artes. Por isso, amanhã (cantar) em um evento de música.

O segundo teste a ser aplicado foi o de tradução ${ }^{13}$. Nele, os participantes recebiam 18 sentenças em espanhol e deveriam traduzilas ao português. A organização desses estímulos é similar à realizada no primeiro teste. As sentenças-alvo foram divididas em dois conjuntos, um que continha 3 sentenças que veiculavam PU, como no exemplo em (28), e 3 com PE, como podemos ver em (29).

(28) Hemos vivido bien en estos últimos días.

'Temos vivido bem nestes últimos dias.'

(29) Nunca he encontrado dinero en la calle.

'Nunca encontrei dinheiro na rua.'

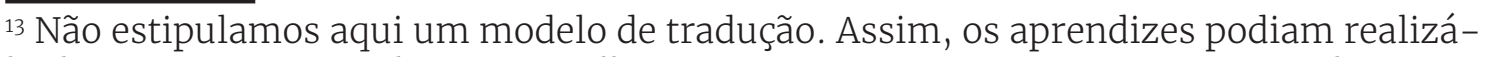
la da maneira como julgassem melhor. No entanto, esperava-se que não realizassem uma tradução palavra-por-palavra das sentenças, mas que informassem como realizariam as sentenças do teste na L2. Todos os participantes do estudo realizaram as traduções do modo esperado.
} 
v. 9 (2)

354-377

maio-ago 2019

As sentenças distratoras também se dividiam em quatro grupos formados por 3 sentenças cada. Os dois primeiros grupos continham sentenças em tempo passado, porém, em um deles, veiculava-se o aspecto perfectivo, por exemplo em (30); enquanto que, no outro, imperfectivo, como em (31). O terceiro grupo, por sua vez, continha sentenças em tempo presente, como vemos em (32), e o último consistia de sentenças com perífrases de futuro, como se pode ver em (33).

(30) La semana pasada no hubo clase de inglés.

'Na semana passada não teve aula de inglês.'

(31) Antes Juan no tenía computadora.

'Antes João não tinha computador.'

(32) Actualmente estudio inglés.

'Atualmente estudo inglês.'

(33) Mañana voy a hacer una prueba.

'Amanhã vou fazer uma prova.'

Os dois testes foram aplicados por meio de um formulário Google. ${ }^{14}$ Os participantes podiam realizá-los no horário e local que desejassem. Apenas eram instruídos a executaras tarefas individualmente e sem apoio de instrumentos que facilitassem sua realização.

\section{Resultados}

Nesta seção, apresentamos, primeiramente, os resultados obtidos por meio da aplicação do teste de preenchimento de lacuna e, em seguida, do teste de tradução. Em relação à análise dos dados, os participantes foram divididos em dois grupos: intermediário e avançado. ${ }^{15}$

No teste de preenchimento de lacuna, com relação às sentenças que veiculavam PU, os participantes em nível intermediário utilizaram três formas verbais. Em 60\% dos casos, foi utilizado o passado composto, como no exemplo em (34); em 33\% dos casos, o presente do indicativo, como visto em (35); e em 7\% dos casos, a perífrase "estar" + gerúndio, por exemplo em (36), como apresentado no gráfico 1.

\footnotetext{
${ }^{14}$ Agradeço ao professor Diego Bussola, professor de língua portuguesa na Universidad Nacional de Rosario, por colaborar com a divulgação dos testes.

${ }^{15}$ Os critérios para divisão dos participantes em intermediário e avançado se basearam no semestre que os aprendizes estavam cursando na graduação e no tempo de exposição ao português como L2.
} 
Gráfico 1 - Formas verbais utilizadas para realizar PU no teste de preenchimento de lacunas por aprendizes em nível intermediário

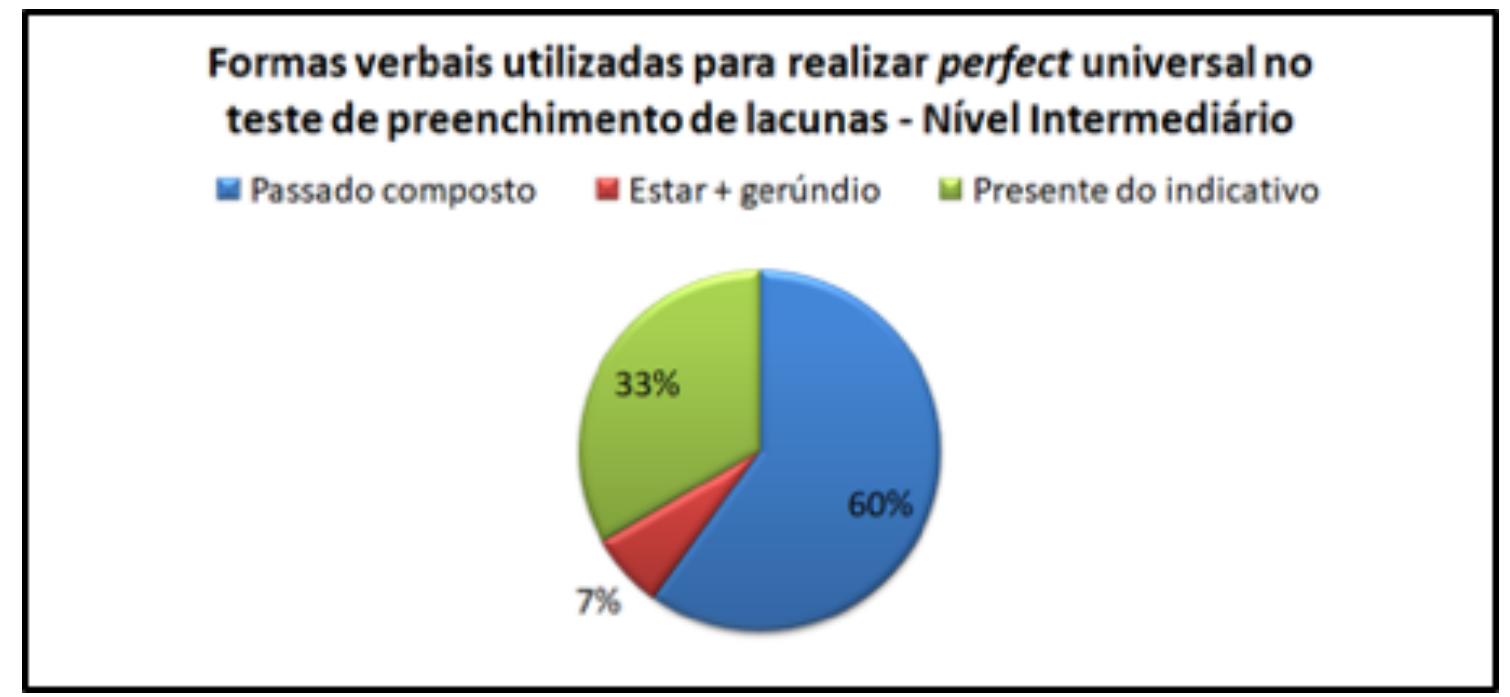

Fonte: Elaborado pelo autor.

(34) Ultimamente Pedro tem estudado bastante para tirar boas notas.

(35) Ultimamente Pedro estuda bastante para tirar boas notas.

(36) Ultimamente Pedro está estudando bastante para tirar boas notas.

Em nível avançado, os aprendizes utilizaram as mesmas formas verbais. Nesse caso, o passado composto foi utilizado em 54\% dos casos; o presente do indicativo em 27\% dos casos; e o "estar" + gerúndio em 19\% dos casos, como verificado no gráfico 2 a seguir.

Gráfico 2 - Formas verbais utilizadas para realizar PU no teste de preenchimento de lacunas por aprendizes em nível avançado



Fonte: Elaborado pelo autor. 
V. 9 (2)

$354-377$ maio-ago 2019
Para realizar linguisticamente o PE, os aprendizes em nível intermediário utilizaram o passado simples em 93\% dos casos, como vemos em (37) e o passado composto em $7 \%$ dos casos, como se pode ver em (38). O gráfico 3, a seguir, ilustra os dados informados neste parágrafo.

Gráfico 3 - Formas verbais utilizadas para realizar PE no teste de preenchimento de lacuna por aprendizes em nível intermediário

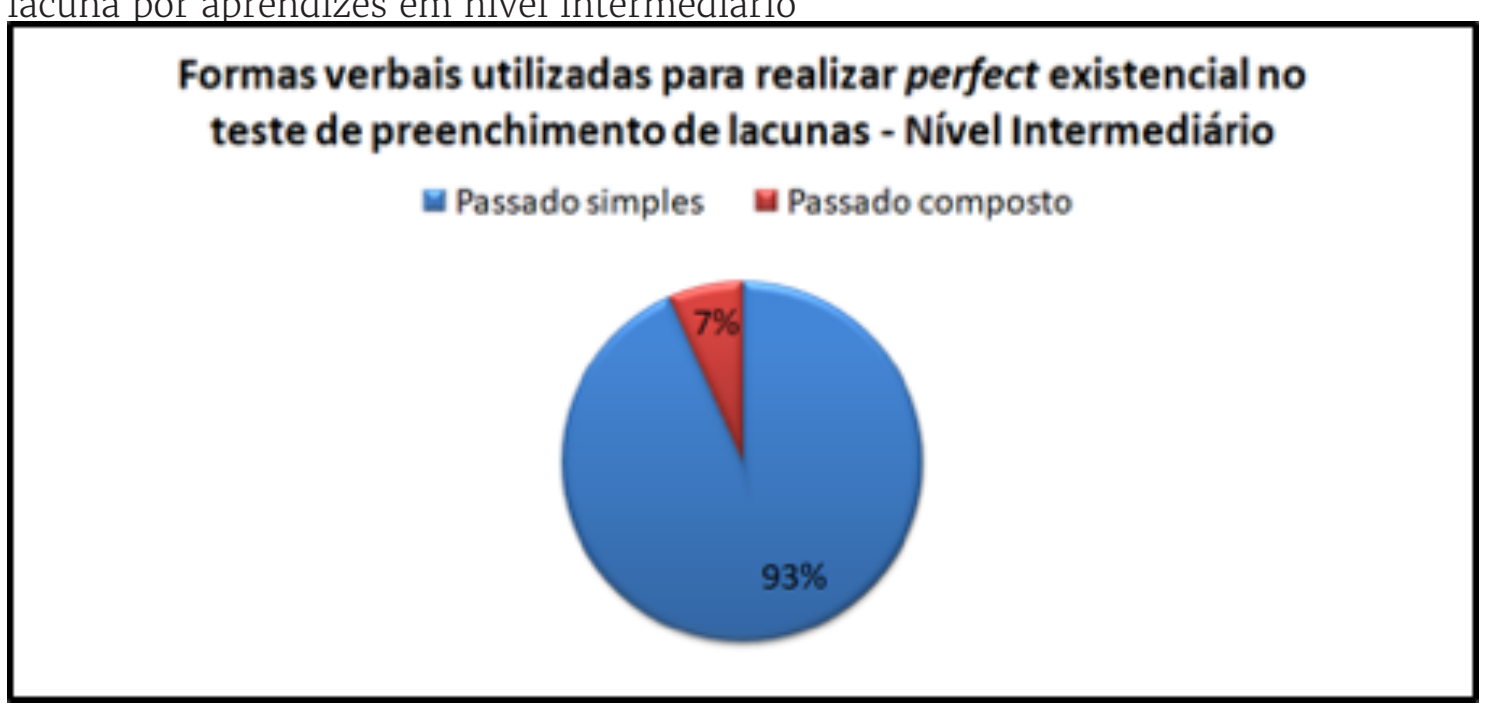

Fonte: Elaborado pelo autor.

(37) Marcela ainda não viajou para Cuba.

(38) Marcela ainda não tem viajado para Cuba.

Os aprendizes, em nível avançado, utilizaram, na maioria dos casos, o passado simples, como ilustrado em (37). Porém, em alguns casos, foi utilizado o presente do indicativo, como vemos em (39). O gráfico 4 apresenta uma síntese dos dados obtidos quanto a essa categoria. 
Gráfico 4 - Formas verbais utilizadas para realizar PE no teste de preenchimento de lacuna por aprendizes em nível avançado

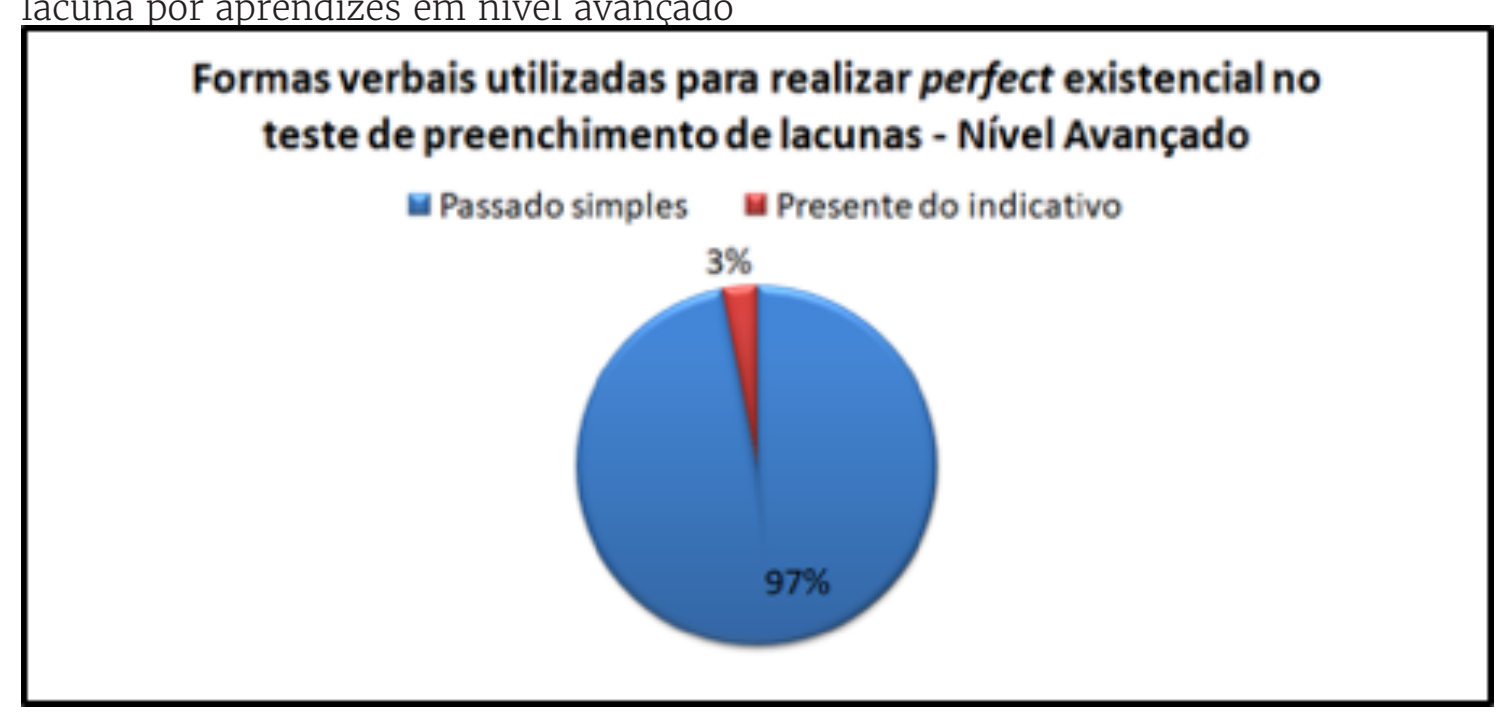

Fonte: Elaborado pelo autor.

(39) Juliana já participa de um evento na Broadway.

No teste de tradução, no tocante às sentenças que veiculavam PU, os aprendizes em nível intermediário utilizaram somente a forma verbal de passado composto, como apresentado no exemplo em (40).

(40) Ultimamente temos encontrado muitos problemas.

Os aprendizes em nível avançado, por outro lado, utilizaram, em $73 \%$ dos casos, o passado composto, como no exemplo em (40) e, em $27 \%$ dos casos, o passado simples, como em (41). O gráfico 5 ilustra os resultados aqui apresentados. 
V. 9 (2)

$354-377$ maio-ago 2019

Gráfico 5 - Formas verbais utilizadas na tradução de sentenças com valor aspectual de PE por aprendizes em nível avancado

\section{Formas verbais utilizadas na tradução de sentenças com} perfect universal- Nivel Avançado

[ Passado composto $\mathbf{U}$ Passado simples



Fonte: Elaborado pelo autor.

(41) Ultimamente encontrei muitos problemas.

Quanto às traduções de sentenças que veiculavam PE, os aprendizes em nível intermediário utilizaram, em 53\% dos casos, o passado composto, como se pode ver em (42), enquanto que, em 47\% dos casos, o passado simples, por exemplo em (43), como ilustrado no gráfico 6.

Gráfico 6 - Formas verbais utilizadas na tradução de sentenças com valor aspectual de PE por aprendizes em nível intermediário

\section{Formas verbais utilizadas na tradução de sentenças com perfect existencial - Nível Intermediário}

Massado composto [ Passado simples

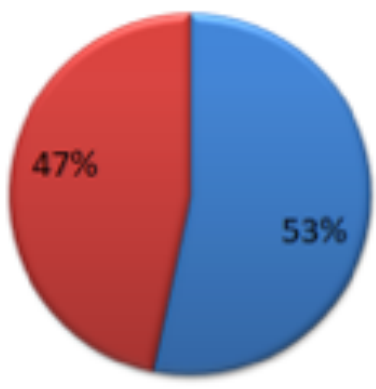

Fonte: Elaborado pelo autor.

(42) Nunca tenho encontrado dinheiro na rua.

(43) Nunca encontrei dinheiro na rua. 
Por fim, as traduções de sentenças que carregavam informação de PE realizadas por aprendizes do nível avançado continham três formas verbais distintas. A predominante foi a de passado simples, totalizando $70 \%$ dos casos, como no exemplo em (43). Foi utilizado também o passado composto em $24 \%$ dos casos, como se pode ver em (42), e, em $6 \%$ dos casos, foram utilizados verbos no passado mais-que-perfeito ${ }^{16}$, como no exemplo em (44). O gráfico 7, a seguir, sintetiza as respostas obtidas nessa parte do teste.

Gráfico 7 - Formas verbais utilizadas na tradução de sentenças com valor aspectual de PE por aprendizes em nível avançado

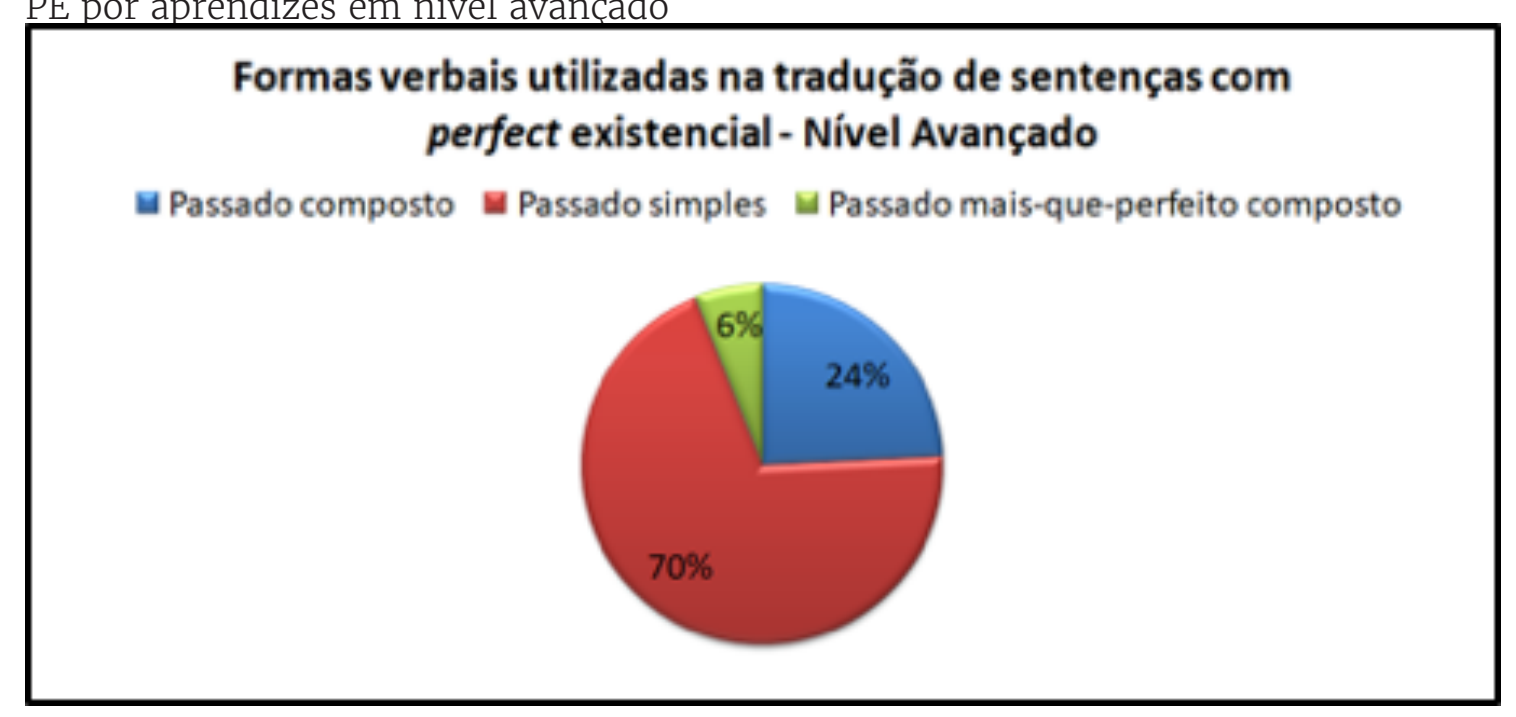

Fonte: Elaborado pelo autor.

\section{(44) João já tinha viajado ao México.}

Na próxima seção, apresentamos a discussão dos resultados obtidos por meio da aplicação dos testes.

\section{Discussão}

Como podemos ver nos dados descritos na seção anterior, os aprendizes, tanto em nível intermediário quanto em nível avançado, no teste de preenchimento de lacuna, utilizaram as morfologias de passado composto, "estar" + gerúndio e presente do indicativo para realizar PU na L2. Essas formas, segundo Novaes e Nespoli (2014), são as que

\footnotetext{
${ }^{16}$ O nome dessa forma verbal, segundo gramáticas tradicionais do português, é "pretérito mais-que-perfeito". Optamos, neste estudo, por denominá-la como "passado mais-que-perfeito" com o objetivo de manter uma simetria com as outras nomenclaturas utilizadas, a saber: "passado simples" e "passado composto".
} 
V. 9 (2)

$354-377$

servem à expressão desse aspecto no $\mathrm{PB}$. Ao observar as porcentagens de uso dessas formas pelos aprendizes, podemos perceber que a mais utilizada foi o passado composto.

De acordo com Jesus et al (2017), a morfologia mais frequente na produção de falantes nativos do PB é o presente do indicativo. Além disso, segundo Mendes (2014), na escolha entre as formas "estar" + gerúndio e "ter" + particípio, os falantes utilizam com muito mais frequência a primeira. Dessa forma, é possível afirmar que os resultados dos aprendizes seguem em uma direção oposta ao que é produzido pelos falantes nativos.

Tal postura, ainda que não seja evidenciada como um caso de transferência de padrões morfossintáticos da L1 para L2, indica que os aprendizes ainda se baseiam em dados presentes em sua língua materna para realizar a escolha entre as morfologias disponíveis na L $2^{17}$.

Essa interpretação parece ainda mais plausível quando observamos os dados do teste de tradução. Nele, os participantes em nível intermediário optaram, em todos os casos, pela morfologia de passado composto, a menos usual no $\mathrm{PB}$, o que indica que os aprendizes não se baseiam na frequência recebida pelo input da L2. Até mesmo nos dados de aprendizes em nível avançado, percebe-se que há também grande preferência por essa forma verbal.

Além disso, alguns participantes do grupo avançado também utilizaram o passado simples para traduzir sentenças que veiculavam PU. Parece haver duas possibilidades de interpretação para esse fato. A primeira delas é a de que os aprendizes, devido à prática de exercícios de tradução em sala de aula, possam ter assimilado que o passado composto pode ser traduzido ao português como passado simples e, por não haver adquirido os contextos em que isso é possível, realizaram as traduções dessa maneira.

Por outro lado, podemos pensar que os participantes podem ter interpretado o evento descrito na sentença de maneira diferente, visualizando-o como um bloco fechado. Nesse caso, a leitura aspectual emergida não foi a de perfect, mas sim de perfectivo, o que explicaria a presença do passado simples nos dados.

Ainda que, no trabalho desenvolvido por Maggessy (2018), tenha sido verificado que o aspecto semântico influencia na escolha das

\footnotetext{
${ }^{17}$ Neste trabalho, não analisamos o modo como os materiais didáticos de português para estrangeiros utilizados na Argentina descrevem o uso do passado composto. No entanto, a investigação da descrição apresentada nesses materiais pode contribuir para o entendimento do processo de aquisição de português como L2 por falantes de EA.
} 
morfologias para realizar o perfect na L2, neste estudo, não é possível afirmar se esse fator atua na realização de PU. No primeiro teste, os verbos utilizados eram atividades e accomplishments e, nesses casos, os aprendizes empregaram as três morfologias disponíveis no português. No segundo teste, por sua vez, havia verbos de estado e achievements, porém apenas foi utilizado passado simples e composto.

Não é possível afirmar que a escolha por essas morfologias se deu baseada nos tipos de verbo presentes nas sentenças, mas parece ser decorrente da metodologia adotada, uma vez que, em todos os dados de PU no segundo teste, houve predomínio do uso do passado composto. Faz-se necessário, então, que, em passos futuros deste trabalho, seja investigado o papel do aspecto semântico na escolha das morfologias disponíveis para expressar PU no português como L2 por falantes nativos de EA.

Há ainda um questionamento que podemos levar em consideração com relação à tradução de sentenças que continham verbos de estado e morfologia de passado composto, como "João tem morado em Madri". Como discutido na fundamentação teórica deste trabalho, não se sabe se construções como essa são realmente gramaticais no português.

Os aprendizes, na maioria dos casos, realizaram traduções com essa morfologia combinada a verbos de estado. Não é possível afirmar que houve uma transferência da L1 para L2, uma vez que nem os estudos sobre o PB apresentam um consenso quanto à (a)gramaticalidade desse tipo de sentença. Porém, é notável que essa construção não é frequente no input oferecido por falantes de PB.

Uma vez que as realizações do PU nas duas línguas apresentam poucas diferenças, não é possível afirmar que há transferência de padrões morfossintáticos da L1 para a L2 pelos aprendizes, independentemente do nível em que se encontram. Ainda assim, é perceptível que a frequência de uso de uma forma na L1 exerce uma forte influência na realização desse aspecto na L2, o que se evidencia pelo predomínio da escolha do passado composto para realizá-lo.

Com relação aos dados de $\mathrm{PE}$, os aprendizes, no teste de preenchimento de lacuna, independentemente do nível em que se encontravam, optaram, na maioria dos casos, por utilizar a morfologia de passado simples. Em algumas poucas ocorrências, foi utilizado o passado composto, por aprendizes em nível intermediário; e o presente do indicativo, por aprendizes em nível avançado. 
v. 9 (2)

$354-377$
Os dados de uso do passado composto podem ser compreendidos como interferência dos padrões da L1 para a L2 pelos aprendizes em nível intermediário. Por outro lado, os dados com presente do indicativo, realizados por falantes de nível avançado podem ser compreendidos como indicadores de que os aprendizes apenas interpretaram o advérbio "já" com outro significado, não havendo transferências de padrões da L1 para a L2.

No PB, o advérbio "já" possui dois valores aspectuais. Um deles indica PE, o que leva a produções com o passado simples, como no exemplo em (16). O outro indica habitualidade no presente, levando a produções com o presente do indicativo, como em "João já sabe nadar, por isso não precisa de aulas". Logo, os dados com presente do indicativo no teste de preenchimento de lacuna podem ser explicados a partir de uma interpretação diferente do advérbio "já".

Assim, parece plausível afirmar que as realizações de PE podem ter sido adquiridas corretamente pelos aprendizes em nível avançado, enquanto que os que cursam o nível intermediário ainda não as têm estabelecidas na sua gramática da L2. Porém, ao verificar os dados do teste de tradução, parte dessa afirmação não se sustenta.

Neste, os aprendizes em nível intermediário, em metade das ocorrências, utilizaram o passado composto e, na outra metade, o passado simples. Uma vez que, no português, o passado composto não pode expressar o $\mathrm{PE}$, pode-se reafirmar que esses indivíduos realmente transferem padrões de realização desse aspecto de sua L1 para a L2.

Os aprendizes de nível avançado, por outro lado, optaram, na maioria dos casos, pela forma de passado simples, morfologia adequada para realização de $\mathrm{PE}$ no $\mathrm{PB}$. Porém, em alguns dados, também foi utilizado o passado composto, o que indica transferência de padrões da L1 para a L2 ${ }^{18}$.

Além disso, algumas traduções foram feitas com verbos na forma de passado-mais-que-perfeito composto. As construções feitas pelos aprendizes com essa forma verbal são possíveis no $\mathrm{PB}$, porém seu uso requer a presença de outra sentença, como no exemplo "João já tinha ido ao México antes de ficar de rico". Nesses casos, não há realização de perfect associado ao tempo presente, mas sim ao tempo passado.

\footnotetext{
${ }^{18}$ Algo que merece destaque é o fato de que a forma mais recorrente para expressar perfect existencial na L2 parece ser também a mais recorrente na L1, apesar de haver variação entre a forma composta. Assim, o uso da forma composta nos dados de L2 pode ser recorrente tanto da frequência de uso da L1 quanto das prescrições da L1 que colocam a forma composta como padrão de uso.
} 
Com relação à relevância do aspecto semântico nos dados de $\mathrm{PE}$, apenas os achievements foram preenchidos/traduzidos quase que completamente com a forma simples, havendo entre todos os dados, apenas um caso em que foi traduzido com a forma composta. Por outro lado, nos outros tipos de verbo, foram utilizadas outras morfologias para expressar essa noção aspectual. Tal fato se assemelha ao que foi proposto por Akerberg (2006) e difere dos dados apresentados por Maggessy (2018), em que os achievements foram considerados propiciadores para a transferência dos padrões de realização do perfect da L1. Os dados deste estudo parecem relacionar-se com o que propõe Andersen (1986), quando afirma que, no processo de aquisição da linguagem, o passado-perfectivo se associa primeiro a achievements. Isso explicaria o fato de esses verbos terem sido majoritariamente realizados/traduzidos com a forma simples.

Com base nos resultados obtidos e na análise realizada, é possível afirmar que a hipótese (i), relacionada à transferência de padrões da L1 para L2 quanto à realização do aspecto perfect por falantes de espanhol nativos da região do litoral da Argentina aprendizes de português como L2 em nível intermediário, foi confirmada, uma vez que utilizaram o passado composto para realizar PE na L2.

Além disso, ainda que não possa ser considerada uma evidência de transferência, a realização de sentenças com PU por meio do passado composto associado a verbos de estados também pode ser entendida como uma forte influência da L1 na L2 desses indivíduos.

A hipótese (ii) de que falantes de espanhol nativos da região do litoral da Argentina aprendizes de português como L2 em nível avançado não transferem padrões da L1 para L2 quanto à realização do aspecto perfect foi refutada, pois foram encontrados dados em que os aprendizes utilizaram a morfologia de passado composto para realizar PE.

\section{Considerações finais}

Este trabalho tinha por objetivo investigar o modo como os falantes nativos do EA realizavam linguisticamente o aspecto perfect no português como L2. Para tanto, foram aplicados dois testes linguísticos, um de preenchimento de lacuna e um de tradução, a aprendizes que se encontravam em níveis intermediários e avançados.

O PU foi realizado, independente do nível em que os aprendizes se encontravam, por meio do passado composto, do "estar" + gerúndio e do presente do indicativo, opções disponíveis no PB. Porém, observou- 
V. 9 (2)

354-377

se que os aprendizes priorizavam a realização por meio do passado composto, que se difere das preferências dos falantes nativos do PB.

Com relação ao $\mathrm{PE}$, os aprendizes utilizaram o passado simples e composto para realizá-lo na L2. Esses dados revelam que os aprendizes, independentemente do nível em que se encontram, transferem padrões morfossintáticos de realização desse aspecto de sua L1 para a L2.

Diante disso, a primeira hipótese do estudo foi confirmada, pois previa que aprendizes em nível intermediário transfeririam padrões de realização de sua L1 para sua L2, enquanto que a segunda hipótese foi refutada, pois indicava que não haveria transferência em dados de aprendizes em níveis avançados.

Não foi possível verificar muito claramente a influência do aspecto semântico nas realizações do aspecto perfect pelos aprendizes. Porém, constatou-se que, diferentemente do que afirma Maggessy (2018), os achievements não favorecem a transferência do uso do passado composto para realização de PE no português por aprendizes de L2 falantes nativos de espanhol.

Faz-se necessário, então, uma investigação mais aprofundada da influência do aspecto semântico no processo de aquisição do perfect no português como L2 por falantes nativos do espanhol. É preciso também que se investigue como os falantes nativos de outras regiões dialetais da Argentina e de outras variedades do espanhol lidam com o fenômeno estudado neste trabalho.

\section{Referências}

AKERBERG, M. Pretérito perfecto compuesto vs. pretérito simple: su adquisición en portugués por hablantes de español. Estudios de Lingüística Aplicada, n. 44, p. 77 - 111, 2006.

ANDERSEN, R. El desarrollo de la morfología verbal en el español como segundo idioma. In: MEISEL, J. (ed.). Adquisición de lenguaje. Frankfurt: Vervuert, 1986. p. 155-138.

ARAÚJO, L. O pretérito em espanhol: uso e valores do perfecto compuesto nas regiões dialetais argentinas. São Paulo: Cultura Acadêmica, 2013.

BURGOS, J. El pretérito perfecto compuesto en el ámbito hispánico. Anuario de Letras, Lingüística y Filología, v. 3, n. 1, p. 87-130, 2015.

COMRIE, B. Aspect: an introduction to the study of verbal aspect and related problems. Cambridge: Cambridge University Press, 1976.

DE PAULA SCOTT, D. Uma questão de aspecto. Trab. Ling. Apl., Campinas, n. 25, p. 33-47, jan./jun. 1995. 
DUARTE, D.; COAN, M.; PONTES, V. A variação entre o pretérito perfeito simples e o pretérito perfeito composto no espanhol argentino. Signo y seña, v. 30, p. 91-107, 2016.

FONTANELLA DE WEINBERG, M. B. (Coord.). El Español de la Argentina y sus variedades regionales. 2. ed. Bahía Blanca: Asociación Bernardino Rivadavia, 2004 .

IATRIDOU, S.; ANAGNOSTOPOLOU, E.; IZVORSKI, R.. Observations about the form and meaning of the perfect. In: ALEXIADOU, A.; RATHERT, M.; VON STECHOW, A. Perfect explorations. Berlin: Mounton de Gruyter, 2003. p. 153-205.

JESUS, J.; MATOS, A.; MARTINS, A.; NESPOLI, J.. O aspecto perfect no português do Brasil. Travessias interativas, v. 14, n. 1, p. 511-526, 2017.

MAGGESSY, A. A realização do perfect no português como segunda língua e como língua de herança por falantes de espanhol do México. Tese de doutorado. Rio de Janeiro: UFRJ, Faculdade de Letras, 2018.

MATOS, A. O aspecto perfect no português do Brasil (PB): uma análise do subtipo perfect de resultado. In: SEMANA DE INTEGRAÇÃO DA UFRJ, 7., 2016, Rio de Janeiro. Anais... Rio de Janeiro: UFRJ, 2016. p. 715-716.

MENDES, R. B. Estar + gerúndio e ter + particípio, aspecto verbal e variação no português. Tese de doutorado. Campinas: Universidade Estadual de Campinas, 2005.

NESPOLI, J. Representação mental do aspecto perfect e suas realizações nas línguas românicas: um estudo comparativo. Tese de doutorado. Rio de Janeiro: UFRJ, Faculdade de Letras, 2018.

; MARTINS, A. A representação sintática do aspecto perfect: uma análise comparativa entre o português e o italiano. Caderno de estudos linguísticos, V. 60, n. 1, p. 30-46, 2018.

NOVAES, C.; NESPOLI, J. O traço aspectual de perfect e suas realizações. Revista FSA, V. 11, n. 1, p. 255-259, 2014.

PANCHEVA, R. The aspectual makeup of Perfect participles and the interpretation of the Perfect. In: ALEXIADOU, Artemis; RATHERT, Monika; VON STECHOW, Arnim. Perfect explorations. Berlin: Mounton de Gruyter, 2003. p. 277-307.

VENDLER, Z. Verbs and times. Philosophical Review, v. 56, p. 143-160, 1967.

WHITE, L. Second language acquisition and Universal Grammar. Cambridge: Cambridge University Press, 2003. 